\title{
A National Obstetrics and Gynecology Residency Education Curriculum: National Needs Assessment
}

\author{
Olga Mutter ${ }^{1, *}$, Jordan Hylton ${ }^{2}$, Stacey Jeronis ${ }^{1}$, David Jaspan ${ }^{3}$ and Marisa Rose ${ }^{1}$ \\ 1 Department of Obstetrics, Gynecology, \& Reproductive Sciences, Temple University Hospital, \\ Philadelphia, PA 19140, USA; stacey.jeronis@tuhs.temple.edu (S.J.); marisa.rose@tuhs.temple.edu (M.R.) \\ 2 Department of Obstetrics and Gynecology, Virginia Commonwealth University Health, \\ Richmond, VA 23298, USA; jordan.hylton@vcuhealth.org \\ 3 Department of Obstetrics and Gynecology, Einstein Healthcare Network, Philadelphia, PA 19141, USA; \\ jaspand@einstein.edu \\ * Correspondence: olga.mutter@tuhs.temple.edu
}

Received: 22 October 2020; Accepted: 4 December 2020; Published: 9 December 2020

\begin{abstract}
While standardized national residency education curricula have been successfully implemented in other specialties, there is no such curriculum in Obstetrics \& Gynecology (Ob/Gyn). With this study, we sought to evaluate: (1) the current state of and satisfaction with resident didactic education (2) perceptions regarding centralization and standardization of resident didactic education and (3) the need for a standardized national Ob/Gyn residency education curriculum. In 2019, a web-based needs assessment survey was administered to residents and program leadership from all $267 \mathrm{Ob} / \mathrm{Gyn}$ residency programs nationwide. Main outcomes were reported with descriptive statistics. A total of 782 (83 program directors, 46 assistant program directors, and 653 residents) participants completed the survey. Respondents represented a diverse range of regions, program types, and program sizes. Almost all (97\%) participants agreed or strongly agreed that residents nationwide should have equal access to high quality $\mathrm{Ob} / \mathrm{Gyn}$ educational resources. Further, $92 \%$ agreed or strongly agreed that core resources should be centrally located. A majority $(78 \%)$ agreed or strongly agreed that there is a need for a national Ob/Gyn residency education curriculum. Our results demonstrate a perceived need for a centrally located, standardized, national residency education curriculum in $\mathrm{Ob} / \mathrm{Gyn}$.
\end{abstract}

Keywords: Council for Resident Education in Obstetrics and Gynecology (CREOG); curriculum development; didactic education; education resources; graduate medical education; national curriculum; needs assessment; program directors; residents; survey

\section{Introduction}

Upon completion of residency training in Obstetrics and Gynecology $(\mathrm{Ob} / \mathrm{Gyn})$, each resident is expected to have a comprehensive knowledge base and clinical competency sufficient for practice. To facilitate residents achieving competencies, every Ob/Gyn residency program is required by the Accreditation Council for Graduate Medical Education (ACGME) to maintain an education curriculum [1]. Additionally, each resident participates in a national knowledge assessment annually with the Council on Resident Education in Obstetrics and Gynecology (CREOG) In-Training Exam. After completion of residency training, graduates are eligible to participate in the written American Board of Obstetrics and Gynecology (ABOG) qualifying examination, the first step towards Board Certification.

There exists a plethora of credible education resources in Ob/Gyn created by organizations such as CREOG and the American College of Obstetricians and Gynecologists (ACOG) to help achieve these 
competencies. However, they are not currently co-located or structured into a format that serves as a comprehensive curriculum for Ob/Gyn residency. In 2020, CREOG published the 12th Edition of Educational Objectives which includes ACOG resources associated with the objectives [2]. While this is an excellent resource, this does not serve as a comprehensive national residency didactic education curriculum. A national curriculum would be hosted on a platform with a structured, cyclic timeline for review of topics with associated resources and assessments and provide a systematic way for residents and programs to cover required content.

Currently, no standardized national curriculum exists in Ob/Gyn and each residency program must develop and maintain its own didactic residency education curriculum. This leads to variability in curriculum content and quality which results in a wide range of resident and faculty satisfaction, resident performance on the annual CREOG exam, and resident clinical knowledge at the completion of training [3-5].

There are ACGME accredited specialties that have successfully created and implemented a standardized national residency education curriculum. General Surgery created the Surgical Council on Resident Education (SCORE, the correlate to CREOG) to standardize and improve resident education by providing residents nationwide with equal access to a common knowledge base through educational resources and a national curriculum [6,7]. The SCORE national curriculum includes a standardized 2-year curriculum composed of weekly topics with associated modules, readings, and quizzes [8]. The curriculum has significantly improved outcomes of residency training including performance on their annual In-Training and Board Exams as well as resident and program leadership satisfaction [9-11]. The SCORE curriculum is ubiquitously used in the field of General Surgery, with $97 \%$ of residency programs participating as of 2018 [12]. Other surgical specialties have added their sub-specialty curriculum content to the SCORE platform, including Vascular Surgery, Pediatric Surgery, Oral and Maxillofacial Surgery, Oncologic Surgery, and Critical Care.

We hypothesize that there is a need for a standardized national residency didactic education curriculum in the field of Ob/Gyn. With this study, we sought to evaluate the current state of and satisfaction with $\mathrm{Ob} / \mathrm{Gyn}$ resident didactic education nationally with the primary outcome of determining the perceptions that $\mathrm{Ob} / \mathrm{Gyn}$ program directors (PDs), assistant program directors (APDs), and residents have of the need for a national $\mathrm{Ob} / \mathrm{Gyn}$ residency education curriculum.

\section{Materials and Methods}

The twelve item web-based survey was developed using the SurveyMonkey online survey platform [13]. The survey was pilot tested at the authors' three corresponding institutions prior to national distribution. The survey questions included assessment of program demographic information, the current use of $\mathrm{Ob} / \mathrm{Gyn}$ educational resources, program-specific didactic education curriculum information, and current satisfaction with resident didactic education. The educational resources included were those created by or in conjunction with ACOG and other national organizations in $\mathrm{Ob} / \mathrm{Gyn}$ as well as the general references of textbooks, faculty materials, and question banks. These educational resources were also the resources selected by participants when the study was pilot tested.

Respondents were further queried about their perceptions regarding the need for centralization, accessibility, and standardization of $\mathrm{Ob} / \mathrm{Gyn}$ residency education and the need for a national $\mathrm{Ob} / \mathrm{Gyn}$ residency education curriculum on a 5 -point Likert scale (from $1=$ strongly disagree to $5=$ strongly agree). Respondents were asked to select which components of a curriculum (including core topics, learning objectives, core readings, additional high yield resources, and quiz questions) they believe should be included if a national curriculum were to be developed. See Figure S1 in Supplementary Materials for survey questions.

All PDs $(n=267)$, APDs ( $n \sim 267)$, and residents ( $n=5144)$ from the 267 ACGME-accredited Ob/Gyn programs nationwide were invited to participate in the survey study [14]. On May 14, 2019, the survey was distributed via email to all programs. PDs and program managers were contacted utilizing email 
addresses obtained on the ACOG website and/or individual program websites. PDs were directly emailed and invited to participate in the survey. Residents and APDs were not contacted directly as their emails are not readily available. Instead, PDs and program managers were asked to distribute the survey to their residents and APDs at their respective institutions for participation in the study.

The survey was open for participants to complete from 14 May 2019 through 18 June 2019. Two reminder emails were sent to complete the survey, the first approximately one week and the second approximately three weeks after the initial survey email. Responses were collected on the SurveyMonkey platform, a secure web-based application [3]. Each participant was limited to one response through the survey platform. Participant responses were anonymous, and participants provided electronic informed consent. Participants were given the option to participate in a raffle for an Amazon gift card. Descriptive statistics were performed using Microsoft Excel 2019 (version 16.26, the Microsoft Corporation, Redmond, WA, USA). Descriptive statistics were reported using means and standard deviations for continuous variables and counts and percentages for categorical variables. This study was deemed exempt by the Temple University Institutional Review Board.

\section{Results}

\subsection{Participants}

A total of 782 (83 program directors, 46 assistant program directors, and 653 residents) participants completed the survey. Given the distribution method of the survey, the true sample size is unknown. Based on the approximate number of potential respondents, our results represent approximately $31 \%$ of the population of PDs (83/267), 17\% of the population of APDs (46/267), and $13 \%$ of the population of residents (653/5144) in the United States during the 2018-2019 academic year, with an overall representation of approximately $14 \%$ (782/5678). A diverse range of program regions, settings, types, and sizes were represented. Respondents represented university-based, community-based/university affiliated, and community-based programs. There was a similar distribution of resident responses from each postgraduate year (Table 1).

Table 1. Program Demographics.

\begin{tabular}{lc}
\hline \multicolumn{1}{c}{ Demographic } & \% (n) \\
\hline Program Region & $15(113)$ \\
Southeast & $43(339)$ \\
Northeast & $23(182)$ \\
Midwest & $8(64)$ \\
Southwest & $11(84)$ \\
West & \\
\hline Program Setting & $71(552)$ \\
Urban & $27(207)$ \\
Suburban & $3(23)$ \\
Rural & \\
\hline Program Affiliation & $58(454)$ \\
University-based & $30(237)$ \\
Community-based/ & $12(91)$ \\
University-affiliated & \\
Community-based & $1(6)$ \\
\hline Residents Per Year in Program & $26(200)$ \\
1-2 & $40(315)$ \\
3-4 & $33(261)$ \\
5-6 &
\end{tabular}


Table 1. Cont.

\begin{tabular}{lc}
\hline \multicolumn{1}{c}{ Demographic } & $\%(\boldsymbol{n})$ \\
\hline Role in Program & \\
Program Director & $11(83)$ \\
Assistant Program Director & $6(46)$ \\
PGY1 & $23(181)$ \\
PGY2 & $22(175)$ \\
PGY3 & $20(157)$ \\
PGY4 & $18(140)$ \\
\hline
\end{tabular}

\subsubsection{Current State of Resident Education}

Of survey participants, $99 \%$ responded that their residency program has a didactic education curriculum, defined as scheduled learning sessions, with or without associated readings. The educational resources most commonly used as part of the didactic education curriculum at $\mathrm{Ob} / \mathrm{Gyn}$ residency programs include ACOG Practice Bulletins, faculty generated materials, and ACOG Committee Opinions. The resources used most for independent learning include ACOG Practice Bulletins, ACOG Committee Opinions, and Ob/Gyn textbooks. The educational materials that respondents found to be the most useful for the CREOG In-Training Exam include ACOG Practice Bulletins, Personal Review of Learning in Obstetrics and Gynecology (PROLOG), and question banks (Table 2). The majority of participants reported that their didactic education curriculum cycles, with a two-year cycle reported most commonly. Some programs have curricula that do not cycle, and many participants responded that they are not sure if their curriculum cycles.

Table 2. Utilization of Education Resources by Participants.

\begin{tabular}{|c|c|c|c|c|c|c|c|c|c|}
\hline Questions & $\begin{array}{c}\text { ACOG } \\
\text { PBs }\end{array}$ & $\begin{array}{c}\text { ACOG } \\
\text { COs }\end{array}$ & Textbooks & PROLOG & $\begin{array}{c}\text { Question } \\
\text { Banks }\end{array}$ & CoreCases & $\begin{array}{l}\text { Exxcellence } \\
\text { Modules }\end{array}$ & $\begin{array}{l}\text { Faculty } \\
\text { Materials }\end{array}$ & N/A \\
\hline $\begin{array}{l}\text { Educational } \\
\text { resources } \\
\text { used by } \\
\text { programs } \\
\text { as part of } \\
\text { the didactic } \\
\text { curriculum }\end{array}$ & $93(724)$ & 84 (658) & $\begin{array}{c}66 \\
(517)\end{array}$ & $\begin{array}{c}64 \\
(502)\end{array}$ & $\begin{array}{c}48 \\
(375)\end{array}$ & $\begin{array}{c}17 \\
(130)\end{array}$ & $\begin{array}{c}12 \\
(95)\end{array}$ & $\begin{array}{c}88 \\
(685)\end{array}$ & $\begin{array}{c}1 \\
(4)\end{array}$ \\
\hline $\begin{array}{l}\text { Educational } \\
\text { resources } \\
\text { used for } \\
\text { independent } \\
\text { learning }\end{array}$ & 97 (753) & $92(713)$ & $\begin{array}{c}75 \\
(581)\end{array}$ & $\begin{array}{c}67 \\
(522)\end{array}$ & $\begin{array}{c}53 \\
(412)\end{array}$ & $\begin{array}{c}7 \\
(52)\end{array}$ & $\begin{array}{c}16 \\
(121)\end{array}$ & $\begin{array}{c}31 \\
(237)\end{array}$ & $2(12)$ \\
\hline $\begin{array}{l}\text { Educational } \\
\text { resources } \\
\text { most useful } \\
\text { for the } \\
\text { CREOG } \\
\text { In-Training } \\
\text { Exam }\end{array}$ & 71 (548) & $50(384)$ & $\begin{array}{c}23 \\
(175)\end{array}$ & $\begin{array}{c}71 \\
(544)\end{array}$ & $\begin{array}{c}57 \\
(436)\end{array}$ & $\begin{array}{c}4 \\
(27)\end{array}$ & $\begin{array}{c}6 \\
(43)\end{array}$ & $\begin{array}{c}11 \\
(85)\end{array}$ & $\begin{array}{c}3 \\
(22)\end{array}$ \\
\hline
\end{tabular}

Data reported as percent of respondents (number of respondents). ACOG, The American College of Obstetricians and Gynecologists; PBs, Practice Bulletins; COs, Committee Opinions; Ob/Gyn, Obstetrics and Gynecology; PROLOG, Personal Review of Learning in Obstetrics and Gynecology; N/A, Not Applicable.

Common challenges reported with programs' didactic education curricula reported by almost half of participants included not enough structure and lack of fully protected education time. Additional challenges included not enough didactic time, low resident participation, not enough resident input in curriculum structure/content, curriculum not updated often enough, changes too often, and too time consuming to maintain.

When asked to rate satisfaction with their current didactic education curriculum at their residency program, more than half of respondents (52\%) are very unsatisfied, unsatisfied, or neutral. However, 
PDs and APDs are more satisfied with their didactic education curriculum than are residents (residents $43 \%$ satisfied or very satisfied vs. PDs $71 \%$ and APDs $72 \%$ satisfied or very satisfied). Ninety percent of residents and $88 \%$ of program leadership (PDs and APDs) agreed or strongly agreed that the didactic education curriculum at their residency program could be improved.

\subsubsection{Perceptions Regarding Centralization and Standardization of Residency Education}

The majority of respondents (63\%) agreed or strongly agreed that all Ob/Gyn residents across the country should learn the same content through their didactic education curriculum, and this percentage increased with decreasing program size (number of residents per year). Almost all participants (97\%) agreed or strongly agreed that residents nationwide should have equal access to high quality $\mathrm{Ob} / \mathrm{Gyn}$ educational resources during their training. Almost all respondents (92\%) and 100\% of respondents from rural programs agreed or strongly agreed that core $\mathrm{Ob} / \mathrm{Gyn}$ educational resources should be in one centralized location. Most (86\%) participants agreed or strongly agreed that they would like to have a curriculum of core education topics for Ob/Gyn residency that is developed and implemented on a national level.

More than three quarters of respondents (78\% total, with $78 \%$ of residents and $76 \%$ of program leadership) agreed or strongly agreed that there is a need for a national Ob/Gyn residency education curriculum. Participants from community-based programs were more likely to agree or strongly agree $(84 \%)$ that there is a need for a national Ob/Gyn residency education curriculum than participants from University-based programs (75\%). Three-quarters (76\%) of participants agreed or strongly agreed that a national $\mathrm{Ob} / \mathrm{Gyn}$ residency education curriculum would improve resident performance on the CREOG In-Training Exam. Residents were more likely to agree or strongly agree that a national $\mathrm{Ob} / \mathrm{Gyn}$ residency education curriculum would improve performance on the CREOG Exam than program leadership (Table 3).

Table 3. Perceptions Regarding Standardization and National Implementation of Obstetrics and Gynecology Residency Education.

\begin{tabular}{|c|c|c|c|c|c|}
\hline Questions & $\begin{array}{c}\text { Strongly Disagree (1) } \\
\text {-Disagree (2) }\end{array}$ & $\begin{array}{l}\text { Neither Agree nor } \\
\text { Disagree (3) }\end{array}$ & $\begin{array}{c}\text { Agree (4) } \\
\text {-Strongly Agree (5) }\end{array}$ & N/A & Mean, 95\% CI \\
\hline $\begin{array}{l}\text { The didactic } \\
\text { curriculum at my } \\
\text { residency program } \\
\text { could be improved. }\end{array}$ & $2(19)$ & $8(61)$ & $90(701)$ & $0.1(1)$ & $\begin{array}{c}4.24,95 \% \mathrm{CI} \\
{[4.19,4.29]}\end{array}$ \\
\hline $\begin{array}{l}\text { Residents } \\
\text { nationwide should } \\
\text { have equal access } \\
\text { to high quality } \\
\text { Ob/Gyn education } \\
\text { resources. }\end{array}$ & $1(5)$ & $2(14)$ & $97(760)$ & $0.4(3)$ & $\begin{array}{c}4.71,95 \% \mathrm{CI} \\
{[4.67,4.75]}\end{array}$ \\
\hline $\begin{array}{l}\text { Core Ob/Gyn } \\
\text { educational } \\
\text { resources should } \\
\text { be in one } \\
\text { centralized } \\
\text { location. }\end{array}$ & $1(8)$ & $7(52)$ & 92 (719) & $0.4(3)$ & $\begin{array}{c}4.51,95 \% \mathrm{CI} \\
{[4.46,4.56]}\end{array}$ \\
\hline $\begin{array}{l}\text { I would like to } \\
\text { have a curriculum } \\
\text { of core education } \\
\text { topics for residency } \\
\text { that is developed } \\
\text { and implemented } \\
\text { on a national level. }\end{array}$ & $4(29)$ & $10(76)$ & $86(675)$ & $0.3(2)$ & $\begin{array}{c}4.31,95 \% \mathrm{CI} \\
{[4.25,4.37]}\end{array}$ \\
\hline
\end{tabular}


Table 3. Cont.

\begin{tabular}{|c|c|c|c|c|c|}
\hline Questions & $\begin{array}{c}\text { Strongly Disagree (1) } \\
\text {-Disagree (2) }\end{array}$ & $\begin{array}{l}\text { Neither Agree nor } \\
\text { Disagree (3) }\end{array}$ & $\begin{array}{c}\text { Agree (4) } \\
\text {-Strongly Agree (5) }\end{array}$ & N/A & Mean, $95 \%$ CI \\
\hline $\begin{array}{l}\text { There is a need for } \\
\text { a national } \mathrm{Ob} / \mathrm{Gyn} \\
\text { residency } \\
\text { education } \\
\text { curriculum. }\end{array}$ & $5(38)$ & $17(133)$ & 78 (609) & $0.3(2)$ & $\begin{array}{c}4.13,95 \% \mathrm{CI} \\
{[4.07,4.19]}\end{array}$ \\
\hline $\begin{array}{l}\text { A national Ob/Gyn } \\
\text { residency } \\
\text { education } \\
\text { curriculum would } \\
\text { improve resident } \\
\text { performance on the } \\
\text { CREOG } \\
\text { In-Training Exam. }\end{array}$ & $4(30)$ & $19(151)$ & $76(596)$ & $0.6(5)$ & $\begin{array}{c}4.13,95 \% \mathrm{CI} \\
{[4.07,4.19]}\end{array}$ \\
\hline
\end{tabular}

\subsubsection{Curriculum Components}

If a national $\mathrm{Ob} / \mathrm{Gyn}$ residency education curriculum were developed, the majority of respondents agreed or strongly agreed that it should include the following: core learning topics (96\%), learning objectives for each topic (80\%), core readings associated with each topic $(91 \%)$, additional high yield resources for each topic (94\%), and quiz questions for each topic (93\%).

\section{Discussion}

The principal finding of this national survey of Ob/Gyn residency programs is a perceived need among residents and program leadership nationwide for a centrally located, standardized national $\mathrm{Ob} / \mathrm{Gyn}$ residency education curriculum.

There were several additional findings that support the principal finding. Our results demonstrate that programs nationwide are using similar education resources for resident didactics, independent learning, and exam preparation. Residents and program leadership report similar challenges with their resident curricula, less than half of residents and program leadership are satisfied with their current didactic resident education, and almost all desire improvement of resident didactics. Residents and program leadership desire centralization, equal accessibility, standardization, and national implementation of resident didactic education content. Program demographics represented a diverse sampling of $\mathrm{Ob} / \mathrm{Gyn}$ programs nationwide [15].

This national survey study demonstrates a perceived need for a centrally located, structured, national residency education curriculum in the field of $\mathrm{Ob} / \mathrm{Gyn}$. While there is limited data in the field of $\mathrm{Ob} / \mathrm{Gyn}$ on this topic, there is research in other specialties including a significant amount in the related specialty of General Surgery. In General Surgery, over ten years ago, a similar national effort to improve residency education led to the creation of a national didactic residency education curriculum which has proved tremendously successful through almost ubiquitous use and improvement in outcomes of residency training [6-11].

There were several strengths to our study. This study was the first to evaluate the need for a national $\mathrm{Ob} / \mathrm{Gyn}$ residency education curriculum, with a majority of respondents indicating a desire for a national curriculum effort. Other strengths include that many different programs and participants were represented in the study and that both residents and program leadership were represented. Most importantly, these results pave the way for residents at all programs to have equal access to standardized education content in the form of a national curriculum. 
There were several limitations to our study. First, we were unable to confirm how many participants received the survey and thus the exact sample size and response rate are not known. This is secondary to the two-step distribution process of the survey that was required due to the lack of accessible resident and APD contact information. Only the PDs were emailed directly. PDs and program managers were asked to forward the survey email to their residents and APDs. The lack of direct contact may explain the lower representation of residents and APDs as compared to the PDs. Not all programs participated in the survey, which yields a risk of nonresponse bias. However, a diverse range of residents and program leadership participated in the study. Additionally, there is an inherent risk of response bias in a survey study as survey questions are answered by self-report. Lastly, there exists the risk of selection bias in that potential participants who were interested in the topic of the study may have been more likely to participate in the study.

\section{Conclusions}

In summary, this national survey of $\mathrm{Ob} / \mathrm{Gyn}$ residency programs demonstrates a perceived need for a centrally located, standardized national $\mathrm{Ob} / \mathrm{Gyn}$ residency education curriculum. Other specialties have created such curricula with tremendous success and almost ubiquitous use. We hope that similar to other specialties, a national $\mathrm{Ob} / \mathrm{Gyn}$ residency education curriculum would lead to improvement in outcomes of $\mathrm{Ob} / \mathrm{Gyn}$ residency training. Most importantly, a standardized curriculum may increase and help standardize resident clinical competency upon completion of residency training and thus ultimately, improve the care that we provide to patients in our field.

Future direction includes designing and implementing a standardized national residency education curriculum in $\mathrm{Ob} / \mathrm{Gyn}$ integrating existing resources, modeled after successful national curricula in other specialties.

Supplementary Materials: The following are available online at http://www.mdpi.com/2673-3897/1/3/17/s1, Figure S1: Needs Assessment Survey.

Author Contributions: Conceptualization, O.M., J.H., S.J., D.J. and M.R.; methodology, O.M., J.H. and M.R.; software, O.M.; validation, O.M., J.H., D.J. and M.R.; formal analysis, O.M.; investigation, O.M.; resources, O.M.; data curation, O.M.; writing-original draft preparation, O.M.; writing-review and editing, O.M., J.H., S.J., D.J. and M.R.; visualization, O.M.; supervision, J.H., S.J., D.J. and M.R.; project administration, O.M.; funding acquisition, O.M., J.H., D.J. and M.R. All authors have read and agreed to the published version of the manuscript.

Funding: This research was funded by the Council on Resident Education in Obstetrics and Gynecology (CREOG) Empower Award.

Acknowledgments: The authors would like to thank the CREOG Empower Award for funding this study, the SurveyMonkey online survey software for providing a platform to develop and distribute the needs assessment survey, and all participants including residents and program leadership who participated in the survey study.

Conflicts of Interest: The authors declare no conflict of interest. The funders had no role in the design of the study; in the collection, analyses, or interpretation of data; in the writing of the manuscript, or in the decision to publish the results.

\section{References}

1. ACGME Program Requirements for Graduate Medical Education in Obstetrics and Gynecology; 2020 Accreditation Council for Graduate Medical Education (ACGME): Chicago, IL, USA, 2019.

2. Council on Resident Education in Obstetrics and Gynecology Educational Objectives: Core Curriculum in Obstetrics and Gynecology, 12th ed.; Council on Resident Education in Obstetrics and Gynecology Education Committee; The American College of Obstetricians and Gynecologists: Washington, DC, USA, 2020.

3. Brown, H.L.; Carson, S.A.; Lawrence, H.C., III. The First National Summit on Women's Health. Obstet. Gynecol. 2018, 132, 755-762. [CrossRef] [PubMed]

4. Holzman, G.B.; Downing, S.M.; Power, M.L.; Williams, S.B.; Carpentieri, A.; Schulkin, J. Resident performance on the Council on Resident Education in Obstetrics and Gynecology (CREOG) In-Training Examination: Years 1996 through 2002. Am. J. Obstet. Gynecol. 2004, 191, 359-363. [CrossRef] [PubMed] 
5. Guntupalli, S.R.; Doo, D.W.; Guy, M.; Sheeder, J.; Omurtag, K.; Kondapalli, L.; Valea, F.; Harper, L.; Muffly, T.M. Preparedness of Obstetrics and Gynecology Residents for Fellowship Training. Obstet. Gynecol. 2015, 126, 559-568. [CrossRef] [PubMed]

6. Sachdeva, A.K.; Bell, R.H., Jr.; Britt, L.D.; Tarpley, J.L.; Blair, P.G.; Tarpley, M.J. National efforts to reform residency education in surgery. Acad. Med. 2007, 82, 1200-1210. [CrossRef] [PubMed]

7. Bell, R.H. Surgical council on resident education: A new organization devoted to graduate surgical education. J. Am. Coll. Surg. 2007, 204, 341-346. [CrossRef] [PubMed]

8. Website: SCORE | General Surgery Resident Curriculum Portal. Available online: https://www.surgicalcore. org/ (accessed on 20 September 2019).

9. Chang, D.; Kenel-Pierre, S.; Basa, J.; Schwartzman, A.; Dresner, L.; Alfonso, A.E.; Sugiyama, G. Study habits centered on completing review questions result in quantitatively higher American Board of Surgery In-Training Exam scores. J. Surg. Educ. 2014, 71, 127-131. [CrossRef] [PubMed]

10. Winer, L.K.; Cortez, A.R.; Kassam, A.; Quillin, R.C.; Goodman, M.D.; Makley, A.T.; Sussman, J.J.; Kuethe, J.W. The Impact of a Comprehensive Resident Curriculum and Required Participation in "This week in SCORE" on General Surgery ABSITE Performance and Well-Being. J. Surg. Educ. 2019, 76, 102-109. [CrossRef] [PubMed]

11. Klingensmith, M.E.; Jones, A.T.; Smiley, W.; Biester, T.W.; Malangoni, M.A. Subscription to the Surgical Council on Resident Education Web Portal and Qualifying Examination Performance. J. Am. Coll. Surg. 2014, 218, 566-570. [CrossRef] [PubMed]

12. Joshi, A.R.T.; Salami, A.; Hickey, M.; Barrett, K.B.; Klingensmith, M.E.; Malangoni, M.A. What Can SCORE Web Portal Usage Analytics Tell Us About How Surgical Residents Learn? J. Surg. Educ. 2017, 74, 133-137. [CrossRef] [PubMed]

13. SurveyMonkey. Available online: surveymonkey.com (accessed on 3 March 2019).

14. National Resident Matching Program, Results and Data: 2019 Main Residency Match ${ }^{\circledR}$; National Resident Matching Program: Washington, DC, USA, 2019.

15. Residency Navigator: Obstetrics \& Gynecology Residency Programs. Doximity Website. 2020. Available online: https://residency.doximity.com/programs?residency_specialty_id=49 (accessed on 9 April 2020).

Publisher's Note: MDPI stays neutral with regard to jurisdictional claims in published maps and institutional affiliations.

(C) 2020 by the authors. Licensee MDPI, Basel, Switzerland. This article is an open access article distributed under the terms and conditions of the Creative Commons Attribution (CC BY) license (http://creativecommons.org/licenses/by/4.0/). 